\title{
DEPOCEN
}

Working Paper Series No. 2018/03

\section{SOUTH KOREAN MULTINATIONAL ENTERPRISES AND VIETNAM SMEs' PARTICIPATION IN GLOBAL PRODUCTION NETWORKS IN THE CONTEXT OF INCREASED ASEAN AND EAST ASIAN REGIONAL ECONOMIC INTEGRATION}

\author{
Ngoc Anh Nguyen ${ }^{1}$ \\ Nguyen Thi Tuong Anh ${ }^{2}$ \\ Nguyen Ngoc Minh ${ }^{1}$ \\ Nguyen Thi Phuong Mai ${ }^{1}$ \\ ${ }^{1}$ Development and Policies Research Center (DEPOCEN), Hanoi, Vietnam \\ ${ }^{2}$ Foreign Trade University \\ The DEPOCEN WORKING PAPER SERIES disseminates research findings and promotes scholar exchanges \\ in all branches of economic studies, with a special emphasis on Vietnam. The views and interpretations \\ expressed in the paper are those of the author(s) and do not necessarily represent the views and policies \\ of the DEPOCEN or its Management Board. The DEPOCEN does not guarantee the accuracy of findings, \\ interpretations, and data associated with the paper, and accepts no responsibility whatsoever for any \\ consequences of their use. The author(s) remains the copyright owner.
}

DEPOCEN WORKING PAPERS are available online at http://www.depocenwp.org 
11

SOUTH KOREAN MULTINATIONAL ENTERPRISES AND VIETNAM SMEs' PARTICIPATION IN GLOBAL PRODUCTION NETWORKS IN THE CONTEXT OF INCREASED ASEAN AND EAST ASIAN REGIONAL ECONOMIC INTEGRATION ${ }^{1}$

Nguyen Ngoc Anh, Nguyen Thi Tuong Anh, Nguyen Ngoc Minh and Nguyen Thi Phuong Mai

\section{Introduction}

During the last decade, Asian countries, especially East and Southeast Asia countries, have witnessed an ever increasing trend of regional integration with the dramatic proliferation of regional free trade agreements (FTAs), both concluded and still in the process of negotiation. This process of regional economic integration has been driven by the mutually reinforcing market forces and trade agreements (regional and 
preferential). According to data from the Asian Development Bank (ADB), the number of FTAs involving at least one Asian country has almost doubled, from 124 in 2005 to 220 in 2016. In addition, there are 67 FTAs being proposed and pending negotiation. ${ }^{2}$ This phenomenon is referred to as the "Asian noodle bowl" with the economies of ASEAN and East Asia becoming increasingly integrated. According to data from ADB, the 16 ASEAN+6 countries (10 ASEAN members plus Australia, PRC, India, Japan, the Republic of Korea and New Zealand) account disproportionately for over 62 per cent of total FTAs (being in effect and in negotiation) of the total 48 ADB member countries/economies in Asia. ${ }^{3}$

The most important market force that drives international trade in recent years is the rise of global production networks operated by multinationals in which firms slice up a production chain into small production stages and then assigning them each to the most cost effective location across borders (ADB 2010; Helpman 2011). Globally operating firms have been taking advantage of these factors to exploit differences in factor prices (i.e. inputs and low-skilled labour) around the world (Blinder 2006; Baldwin 2011) and multinationals are at the forefront of global production networks taking advantage of reductions of trade barriers, rapid advancements in production technology, and a decrease in transport and communication costs as explained by Athukorala (2013). He explains that firstly "rapid advancements in production technology have enabled the industry to slice up the value chain into finer, "portable', components" (i.e. modular production technology with "standard fragments"); secondly "technological innovations in communication and transportation have shrunk the distance that once separated the world's nations, and improved speed, efficiency and economy of coordinating geographically dispersed production process", and thirdly the "liberalization policy reforms across the world over the past four decades have considerably removed barriers to trade and foreign direct investment (FDI)".

Although such fragmented production has been argued to be beneficial as it allows economies, especially in Asia thanks to its strong intraregional and international links, and its adeptness at transferring and absorbing new production technologies, to specialize in narrower niches to enter international markets with a more limited range of skills 
than previously (ADB 2010, p. 62), a major area of concern amongst policymakers has been the extent to which small and medium-sized enterprises (SMEs) are participating and benefitting from regional economic integration. It is a valid concern given that about 95-99 per cent of all firms in the region are SMEs. Furthermore, SMEs are also likely to be more resource-constrained (compared to large firms) to take advantage of the benefits from trade and investment liberalization.

Like other countries in the region, during the last decade, global production networks operated by large multinational enterprises (MNEs) have become increasingly relevant for Vietnam, as the country witnesses more and more global production facilities being set up by MNEs, from lower-skilled sectors like garment and textile to hightechnology sectors like electronics. Among other factors, this phenomenon has been partly attributed to the recent proactive engagement of Vietnam through various FTAs like the ASEAN-Korean FTA, VietnamEU FTA, the Trans-Pacific Parnership (TPP) and the like. ${ }^{4}$ The arrival of many MNEs has helped to integrate the country deeper into the global production networks in various sectors from furniture, garments to electronics. For example, the arrival of the largest electronics giants such as Intel, Nokia, and most notably Korean MNEs such as Samsung and LG together with their first-tier suppliers such as Foxcon, has turned Vietnam into one of the largest electronic production hubs in the global production networks.

Like many other developing countries, the private sector of Vietnam is mostly made up of SMEs which account for more than 90 per cent of all firms. The country shares the same above-mentioned policy concerns, that is, beyond the initial direct effect on the local economy in terms of capital injection and employment creation, the question that a developing country like Vietnam is facing is how to stimulate the diffusion of technology and productivity gains from the FDI sector in general and these global production networks in particular to other parts of the economy. Despite the fact that FDI has been widely perceived as a panacea for developing countries as a way to reduce poverty and kick-start sustainable modern industries, most Vietnamese domestic firms, especially SMEs, cannot yet participate in the global production networks through which Vietnam can improve its technology level. Policies should be implemented to make FDI firms become more connected with the rest of the economy rather than as an "enclave" FDI sector. 
This question is particularly relevant in the process of Vietnam's transition from a lower to a higher middle-income country status because despite the potential positive effects of spillovers, the presence of these MNEs and their production networks can also have negative effects on local firms (Damijan et al. 2013). The capital, managerial, technological and know-how advantages of FDI firms enable them to take over the market of domestic firms, forcing them into less efficient scales and less productive activities. Moreover, MNEs which are attracted to a country due to its low labour productivity may contribute to that country's falling into low productivity trap (Seguino 2005). Without appropriate policies the arrival of MNEs could result in the so-called "enclave economy", the benefits of which are confined to an international sector not connected to the wider economy (Gallagher and Zarsky 2007).

Despite their importance, there is currently a lack of systematic and comprehensive research on these issues. This study is an attempt to fill in this gap of the literature. In particular, the chapter seeks to address two related questions:

- Firstly, how regional economic integration (e.g. AEC, FTA) has affected MNEs in their investment decisions and operations?

- Secondly, what is the nature and extent of linkages that MNEs have developed with SMEs in Vietnam (host country), and to the extent possible, how is this relationship shaped by regional economic integration?

To address these inter-related questions, in this chapter, we adopt a case study approach. We focus on Korean MNEs, their investment decisions and operations in Vietnam as the host country in response to the increasing regional integration trend and the linkages with their local Vietnamese SMEs. Vietnam is selected as a country for study because it is part of ASEAN, recently opened up to the world economy and actively engaged in numerous FTAs, including the ASEAN Economic Community (AEC), EU-Vietnam FTA, TPP and many other bilateral agreements. Korean MNEs are selected because Korea is one of the biggest foreign investors in Vietnam. But more importantly, Vietnam has been experiencing a recent wave of inbound FDI from Korean MNEs in both traditional manufacturing sectors like garment and more advanced sectors like electronics. One of the greatest challenges for addressing these questions is data availability. In this study, 
instead of relying on quantitative data analysis and modelling, we combine descriptive data statistics (both administrative data and survey data) with qualitative data collected from in-depth interviews with both Korean MNEs and their local partners as well as policymakers.

Although we focus largely on the manufacturing sector, we conducted our in-depth interviews mostly with CEOs of firms in two main sectors: electronics and apparel. Apparel is selected because Vietnam has developed a vibrant domestic apparel processing industry during the last 20 years. Vietnam is one of the biggest apparel exporters in the world, ranked 5th after China, Bangladesh, Italy and Germany. Electronics is not a new industry in Vietnam. During the early years of economic reform, there were attempts to jump-start the sector but failed. However, during the last five to seven years, the electronics sector has been experiencing a spectacular export growth thanks to the arrival of many electronics giants, including Korean MNEs. The remainder of the chapter is structured as follows. In the next section, we present our analysis on the first question, and in section three we focus on the linkages between MNEs and SMEs. Section four offers some concluding remarks.

\section{Vietnam's Regional Economic Integration and Korean MNEs}

\subsection{Vietnam-Korean Bilateral Trade and Investment Relations}

Vietnam and South Korea have continuously developed a significant bilateral trade and investment relation since Vietnam's opening-up to the global economy and established diplomatic and economic relations with South Korea. According to the latest data, Vietnam-Korea trade grew continuously during the last ten years (see Figure 11.1), with the total trade value reaching US\$28.9 billion in 2014. During the period 2005-14, it had a composite average growth rate of 23.7 per cent. Vietnam's import accounted for the major share of this bilateral trade. In 2014, Vietnam's imports from Korea (Rep.) amounted to roughly US\$21.7 billion, tripling the export value (US\$7.2 billion). In the last ten years, Vietnam's deficit in trade with Korea (Rep.) widened significantly to reach US\$14.6 billion in 2014 from only US\$2.9 billion in 2005. Looking at the structure of exports and imports between the two countries could reveal the underlying structure and 
Vietnam-South Korea Bilateral Trade Flows (USD billion)



Source: UN Comtrade..

the complementarity. Capital and/or technology-intensive products are imported most by Vietnam. Electrical equipment is imported most by Vietnam from Korea. Its import value at US\$5.7 billion, accounted for over one-fourth of total imports from Korea. The other major product groups include textile materials (10.4 per cent) and telecommunications and sound-recording and reproducing equipment (10.1 per cent). Apparel and clothing accessories stood out to be the most important export by Vietnam to the South Korean market. In 2014, these products generated a total revenue of US $\$ 2.0$ billion, corresponding to a 28.1 per cent share of Vietnam's exports to South Korea.

Vietnam has successfully attracted large volumes of FDI, reaching levels of around US\$10-12 billion per year over the last six years. According to the General Statistics Office, for 2015 there were over 2,000 newly registered FDI inflow projects with total capital of US\$15.6 billion, along with another 814 projects expanding their investment to US\$7.2 billion by the end of 2015, a year-on-year increase of 12.5 per cent. According to Foreign Investment Administration under the Ministry of Investment Planning of Vietnam, South Korea has become one of the biggest foreign investors in Vietnam (see Table 11.1). Electric and electronics industries are Korea's main investment as well as a number of light industries, such as textile and shoe. 
TABLE 11.1

Key Investors in Vietnam (as of February 2016)

\begin{tabular}{rlrc}
\hline TT & \multicolumn{1}{c}{ Country } & Number of Project & $\begin{array}{c}\text { Total Registered Capital } \\
\text { (US\$ million) }\end{array}$ \\
\hline 1 & South Korea & 5,058 & 45,390 \\
2 & Japan & 2,965 & 38,860 \\
3 & Singapore & 1,570 & 36,050 \\
4 & Taiwan & 2,491 & 31,160 \\
5 & EU & 1,788 & 24,300 \\
6 & British Virgin Islands & 632 & 19,58 \\
7 & Hong Kong & 992 & 15,850 \\
8 & Malaysia & 528 & 13,660 \\
9 & US & 791 & 11,320 \\
10 & China & 1,336 & 10,390 \\
\hline
\end{tabular}

Source: Foreign Investment Administration, Ministry of Planning and Investment.

\subsection{The Impact of Regional Integration and Investment Decision by Korean MNEs}

This section of the chapter aims to explore how regional economic integration has affected the operation of Korean multinational firms and their relationship with both domestic and international SMEs to give a better idea of East Asian regional economic integration in the country. To assess the impact of regional integration on investment decision, ideally, we would like to observe the investment decision made by "similar" firms before and after the so-called regional integration "event". However, we do not have such luxury. Instead, in the context of this study, we rely on some aggregate macro data and qualitative data we obtained from in-depth interviews with Vietnamese policymakers and representatives of MNEs and SMEs in Vietnam.

The FDI inflows from South Korean firms into Vietnam during 2005-15 are presented in Figure 11.2. There are some indications that trade liberalization does have some impact on the inflow of Korean FDI into Vietnam, especially at two important points: The ASEAN-South Korea FTA in 2005 and the Vietnam-South Korea FTA in 2015. 
FIGURE 11.2

South Korean FDI Inflows into Vietnam, 2005-15

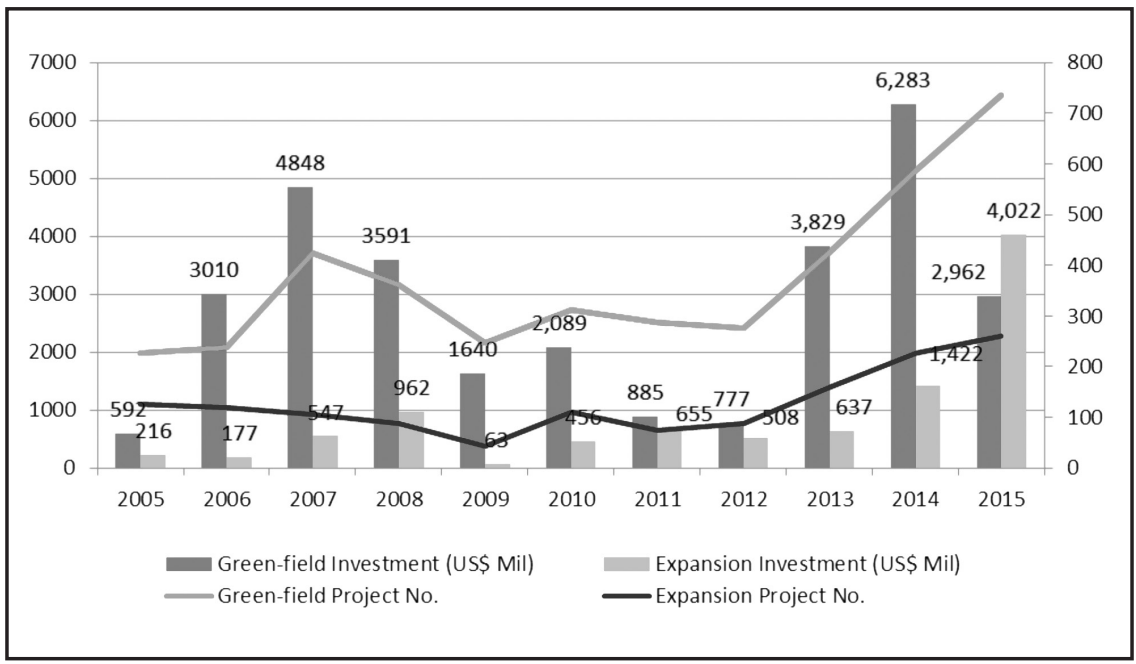

Source: Foreign Investment Administration, Ministry of Planning and Investment.

- First is the sharp increase of Korean FDI inflows (both in terms of investment amount and number of projects) into Vietnam during 2006-8 when the ASEAN-South Korea FTA was concluded (effective in 2007). During this period, there were large investment inflows by MNEs such as the Posco Steel BRVT project in 2006 (worth US\$1.13 billion), Keangnam real estate in Hanoi in 2007 (worth US\$500 million), Hyosung textile in Danang in 2007 (worth US\$368 million), and Inpyung real estate in Hanoi in 2008 (worth US\$660 million).

- Second is another even larger increase of Korean FDI inflows in the build-up to the Vietnam-Korea FTA in December 2015 which promises sharp cut on import duties for Vietnam's agricultural products and materials for textile, electric and electronics, and automobile parts from Korea. During this period, there were many mega projects. For example, in 2010 Posco Steel BRVT invested US\$700 million; in 2013, LG Electronics invested US $\$ 1.5$ billion in Hanoi; and Samsung Electronics invested US\$1.23 billion in Thai Nguyen. In 2014, Samsung Electronics further invested US\$3 billion while Samsung Display invested another US\$1 billion in 
Bac Ninh which was expanded further to US\$3 billion. In 2015, Posco Steel BRVT invested US\$1.13 billion.

While such aggregate data is illuminating to some extent, we explore further the linkage between the two by conducting a number of interviews with both policymakers and South Korean investors in Vietnam and their local partners.

We conducted an informal interview with a senior policymaker from a FDI-relevant agency in the Ministry of Planning and Investment. This official believes that regional integration has an important impact on MNEs' decisions on investment in Vietnam and suggests that there would be strong FDI inflow in such sectors as electronics, distribution, wholesale and retail, real estate, tourism, food and food processing, textile, and agriculture. This official also holds the view that the expansion of Korean transnational corporations (TNCs) such as Samsung, Doosan, LG, Posco, Taekwang, Hyosung, and Kumho has led to significant increase of their satellite Korean SMEs due to the follow-the-leader effect. For example, in the case of Samsung, not only they have constructed their electronic and electronics plants, but also expressed interest in Vietnamese retail market. Korean retailer Emart, which is owned by Samsung's relatives, entered Vietnam with an investment of US\$60 million and is expected to be operational by the end of 2015 or early 2016.

Previous surveys and anecdotal evidence on the factors that influence investors' decision to invest in Vietnam are abundant. Besides citing an abundant and young labour force as an important factor, foreign investors often cite Vietnam's geographical position near global supply chains, the growing consumer market, expected improvements in the business climate upon completion of the TPP, and relative political and economic stability. Investors are also showing an increasing desire to diversify their manufacturing base in Asia away from China as a reason they opted to invest in operations in Vietnam. This phenomenon is highly due to Chinese economic development plan that has moved up the value chain in manufacturing. Instead of China, Vietnam takes a call to action on the "China plus one" model and successfully invites foreign investment using the advantage of its abundant human resources. However, evidence on the impact of regional integration through such agreements like Vietnam- 
South Korea FTA, or ASEAN-Korea FTA on the decision of Korean MNEs are scant. To explore this issue, we conducted a number of interviews with Korean invested firms in Vietnam as well as their local partners.

There are mixed evidence on the impact of regional integration in MNEs' investment decisions and the picture is quite complex. In this section, we focus on the garment sector. We interview two Korean garment firms in Vietnam, a medium-size and a large one. ${ }^{5}$ In the interview with the medium-size Korean-invested garment company with around 400-500 employees established in 2005 in Vietnam, the manager suggests that in theory they would benefit from the zero duty rate provided in the Vietnam-Korea FTA. However, getting such preferential treatment is difficult as it is not easy to obtain the certificate of origin for exports from Vietnam as the country still relies too much on imports of materials from China. Similarly, the manager is quite cautious of the prospect of the TPP. While they have been watching the development of the TPP, they are worried about the actual implementation as there are strict requirements such as the yarn-forward criteria, thus rendering garments produced in Vietnam not eligible for preferential treatment in TPP. Despite the initial not-so-positive assessment toward Vietnam-Korea FTA and the TPP, the manager reveals that they are exploring possibilities to invest in new product lines that could take advantage of the FTA and TPP. For example, they are considering production of higher quality products that could use materials of Vietnamese origin. The larger firm has been investing in Vietnam for a relatively long time, since 2002, and expanded its operation in 2009 with a total workforce of 8,000 employees. According to the manager of this garment company, Korean enterprises are investing in Vietnam due to Vietnam's abundant labour force and tax incentives. On top of that the recent Vietnam-Korea FTA would be an important factor attracting Korean investors to Vietnam. The TPP is also assessed positively as 99 per cent of the company's export is to the U.S. market. The company, besides having two large factories in the north of Vietnam, has just opened a new company based in Ho Chi Minh city (south of Vietnam) in the expectation that new orders are coming and they would be able to handle these new orders by themselves rather than through the headquarter in Korea. 


\section{Vietnamese SMEs' Integration into the Korean MNEs' Global Production Networks}

To address the second research question, in this section, we explore the state of Vietnamese SMEs' participation in regional trade, production networks, and investment activities. In doing so, we also explore the enabling factors and obstacles to SME participation in regional trade, production networks, and investment activities.

\subsection{An Overview of Vietnamese SMEs' Participation in Global Production Networks}

Although the concept of participating in global production networks is intuitively clear, operationalizing this concept and measuring it is not so easy. As a proxy for participating in global production networks, we rely on a number of operational measures: exporting, importing, supplying to FDI firms, and subcontracting for other firms. In this study we use two data sources:

(i) The Survey of Small and Medium Scale Manufacturing Enterprises (SMEs) in Vietnam from 2009 to 2013 conducted consistently by the Ministry of Labour, Invalid and Social Affairs (MOLISA) and the Stockholm School of Economics (hereafter the MOLISA SMEs survey);

(ii) The Survey of Small and Medium Scale Manufacturing Enterprises (SMEs) commissioned by ERIA and conducted by DEPOCEN (hereafter the ERIA survey).

The former survey is conducted every two years in ten provinces of Vietnam and provides information on about 2,500 firms in 12 industries each year, focusing on SMEs in Vietnam. The latter is a special survey commissioned by ERIA to look specifically at the participation of Vietnamese SMEs in three sectors.

As indicated in Table 11.2, the level of participation of Vietnamese SMEs in global production networks in general is very limited. The percentage of SME exporting firms is very small, according to the MOLISA survey data, although there is a small increase from 5.8 per cent in 2009 to 6.4 per cent in 2013. Similarly, the number of importing firms is small, at about 3.5 per cent of the total number of firms. The 
TABLE 11.2

Vietnamese SMEs' Participation in Global Production Networks

\begin{tabular}{lccccccccccc}
\hline & \multicolumn{4}{c}{$\begin{array}{c}\text { Supplier } \\
\text { to FDI }\end{array}$} & \multicolumn{1}{c}{ Importing } & $\begin{array}{c}\text { Import } \\
\text { from } \\
\text { ASEAN }\end{array}$ & Subcontract \\
\cline { 2 - 12 } Sample Size & No. & $\%$ & No. & $\%$ & No. & $\%$ & No. & $\%$ & No. & $\%$ \\
\hline 2009 & 2,659 & 155 & $5.8 \%$ & 130 & $4.9 \%$ & 92 & $3.5 \%$ & 32 & $1.2 \%$ & - & - \\
2011 & 2,552 & 100 & $3.9 \%$ & 132 & $5.2 \%$ & 84 & $3.3 \%$ & 37 & $1.4 \%$ & - & - \\
2013 & 2,533 & 163 & $6.4 \%$ & 119 & $4.7 \%$ & 92 & $3.6 \%$ & 37 & $1.5 \%$ & - & - \\
2015 & 208 & 77 & $37.0 \%$ & - & - & 71 & $34.1 \%$ & 14 & $6.7 \%$ & 88 & $42.3 \%$ \\
\hline
\end{tabular}

Source: MOLISA SMEs survey 2009, 2011, 2013; and ERIA survey, SME Participation in ASEAN and East Asian Regional Economic Integration 2015.

number of firms importing from ASEAN countries is even smaller, staying at just about 1 per cent. Interestingly, in comparison with figures on importing and exporting, there are about 5 per cent of firms who are suppliers to FDI firms in Vietnam. The ERIA survey provides much higher figures on these aspects. This is because the sectors covered in the survey are export-oriented sectors of Vietnam such as wood processing and garment. The overall conclusion from these surveys is that the participation of Vietnamese SMEs in global production networks in general is still limited. However, for sectors that are more export-oriented, the level of participation is much higher. This finding is somewhat consistent with previous study on ASEAN by Wignaraja (2012) who reported that the larger firms are playing bigger roles than SMEs in global production networks. However, the number reported in the SME survey is even lower than that reported by Wignaraja (2012), which could be explained by the nature of the sample. Still the number reported in the ERIA survey is more comparable with Wignaraja (2012). Comparing between ASEAN countries, he reported a higher participation rate in more advanced countries like Thailand and Malaysia and lower rates in such countries like Vietnam, Philippines and Indonesia. This is also consistent with popular opinion that firms in Vietnam are not yet ready to joint global production networks. ${ }^{6}$ 


\subsection{Participation in Global Production Networks in the Traditional Apparel Sector}

\subsubsection{Overview of the sector}

The apparel sector is one of the key sectors for Vietnam and has long been considered an important light industry for the country. The Ministry of Industry and Trade approved the Master Plan for the Development of Vietnam's Textile and Garment Industry until 2020, with an orientation to 2030 in Decision No. 3218/QD-BCT dated 11 April 2014. This official document specified the industry development perspectives and objectives, the product development orientation and the regional planning. According to Statistical Yearbook of Vietnam 2014, the industry consists mainly of SMEs with nearly 85 per cent of the total 5,167 enterprises having less than 300 employees, a threshold commonly used to distinguish medium from small enterprises. The sector employs more than 2.5 million workers and accounts for about 25 per cent of the labour in the industrial sector in Vietnam.

Along with phones and mobile devices, apparel is the major export sector. The sector's export value reached US\$20.1 billion in 2014, 16.7 per cent higher than in 2013, with a composite average growth

TABLE 11.3

Top Ten Largest Exporters of Apparel Worldwide, 2014

\begin{tabular}{rlccr}
\hline Rank & Exporter & $\begin{array}{c}\text { Value } \\
\text { (USD billion) }\end{array}$ & $\begin{array}{c}\text { Share } \\
(\%)\end{array}$ & $\begin{array}{c}\text { Growth } \\
\text { (\%) }\end{array}$ \\
\hline 1 & China & 191.4 & 39.1 & 5 \\
2 & Bangladesh & 24.6 & 5 & 4.6 \\
3 & Italy & 23 & 4.7 & 6 \\
4 & Germany & 20.1 & 4.1 & 7.3 \\
$\mathbf{5}$ & Vietnam & $\mathbf{2 0 . 1}$ & $\mathbf{4 . 1}$ & $\mathbf{1 6 . 7}$ \\
6 & India & 19.9 & 4.1 & 3.7 \\
7 & Hong Kong & 19.4 & 4 & -6.4 \\
8 & Turkey & 18 & 3.7 & 8 \\
9 & Spain & 12.4 & 2.5 & 9 \\
10 & France & 10.9 & 2.2 & 4.4 \\
\hline
\end{tabular}

Source: UN Comtrade and Depocen. 
rate of 17.3 per cent over the period 2010-14, resulting in positive gains in global market share. Consistent with findings from the ERIA survey (see above), the last two decades have witnessed rapid and active participation of Vietnam apparel firms in global value chains. In 2014, Vietnam became the fifth largest exporter of apparel worldwide thanks to its gaining global market share and continued high growth rates. ${ }^{7}$

An important point to note is that Vietnam's apparel export depends on foreign traders who play a very important role as intermediaries in the apparel supply chain of Vietnam garment producers. These traders are generally from Hong Kong, Taiwan and South Korea with whom top leaders of global retailers/brands from the European Union, Japan and the United States, and their own international top brands rely to develop their supplier networks in Vietnam in order to reduce transaction cost of contracting and sourcing from much smaller Vietnamese garment factories although recently these top global retailers/brands have established contacts with larger Vietnamese firms.

According to the Vietnam Textile and Apparel Association (VITAS), the cut-make-trim (CMT) model which yields the lowest value added is still a dominant mode of production/business in Vietnam with about 85 per cent of the enterprises using this model as their primary businesses in 2013. ${ }^{8}$ Most of Vietnam's apparel enterprises only act as the subcontractors by performing the outsourcing contracts for the mass merchant retailers, specialty retailers, brand marketers and brand manufacturers. The orders are normally accompanied by the product design and specifications. As a result of this CMT, despite the high level of Vietnam's participation in these global value chains, the benefit of participation has been questioned. In addition, competing at the lower cost segment (i.e. cheap labour and low value added segment) of the highly fragmented global apparel value chain drives down the margin of the Vietnamese SMEs, at the same time strengthen the buyers' power as they have more options to consider in order to select the most appropriate partners. Another weakness of apparel production in Vietnam is the fact that the sector relies heavily on imported fabric materials (mostly from China), especially in the production of apparel for export. The value of fabrics imported was estimated at US\$9.4 billion in 2014, of which US\$4.7 billion was for Chinese fabrics. South Korea was the second largest supplier with a 19.5 per cent share, followed by Japan (5.9 per cent). 
The fragmentation makes the apparel sector become highly competitive both globally and within Vietnam. As the international buyers source their products worldwide, competition occurs not only among the exporting companies from Vietnam, but also between Vietnamese companies and those from other countries, including Bangladesh, Cambodia, China, Indonesia, Pakistan, etc. as well as multinational manufacturers. In 2013, there were over 5,000 apparel enterprises in Vietnam, nearly 5,000 garment factories in Bangladesh and more than 15,000 in China (OECD Observer). Although it does not mean that all of these companies are capable of integrating into the international trade or global production networks, these figures show a great deal of how numerous the apparel exporters worldwide are, and how competitive the sector is. In Vietnam, for example, the individual shares of the leading exporters were less than 2 per cent of Vietnam's garment industry in 2014, such as Viet Tien (1.85 per cent), Tinh Loi (1.36 per cent), Hansae Vietnam (1.16 per cent) and HANESBRAND Vietnam (1.06 per cent), implying a large number of apparel exporters and fierce competition.

\subsubsection{Participation in Korean apparel production network}

There are evidence that it is possible for Vietnamese apparel SMEs to integrate into apparel global production networks with and through Korean MNEs. These global chains may either be led by a Korean MNE or sourced through a Korean MNE. Our interview with a mediumsized Vietnamese apparel processing Kien Giang company suggests that the company may be able to supply directly to orders placed by international MNEs, including Korean MNEs. However, it is not always possible to link up with these global production networks. There are at least two issues.

First is the nature of the apparel production network and the capacity of SMEs. Typically in the global market, the larger MNEs prefer to source from a few, but large manufacturers in order to avoid the unnecessary time and transaction costs. The desirable vendors must be able to offer consistent quality, reliable delivery, short lead times, large-scale production, flexibility, competitive prices, full package services and social compliance. The implication is that in order to directly work with the global buyers, the suppliers need to be operating at a large scale and with sufficient management skills so as to be capable of completely fulfilling their obligations. ${ }^{9}$ 
For the smaller SMEs, on their own, they would not be able to deliver on large orders. Their strategy is to form an informal network of smaller garment processing factories in such a way that they could together deliver the large orders/assignments and share the risk of having to invest into production lines that may only operate part of the time. This informal network could serve the smaller factories to a certain extent for some time, but at the same time put a cap on their growth and inherently become a trap for these SMEs. Without serious investments in production capacity, the smaller factories would not be able to secure regular and frequent orders for their operations. Many enterprises act as the subcontractors to the larger national manufacturers by carrying out solely the CMT activities and finishing services. In this case, the contracts are often only short term or seasonal, and the manufacturers operate on an order-by-order basis. The entry barriers to this segment are evaluated to be low as it requires only few investment and low labour skills while it is quite easy for the buyers to switch from one manufacturer to another. There are evidence that SMEs could learn from and perform some higher value-added stages such as design and reverse-engineering for MNEs, but they do not value these activities yet. For example, Kien Giang company could perform certain stages of designing and cutting for its MNE clients, but the company do not see this as moving up the value chain as the "benefit" of doing so is too small for the company.

The second issue relates to the investment strategy of MNEs in Vietnam. Different from other MNEs from the U.S. or European or truly global MNEs which only source their products from Vietnamese garment factories and rarely from their own factories in the host country, these Korean MNEs are investing in Vietnam and setting up their own production facilities to take advantage of cheap labour. Our interviews with a number of Korean FDI apparel MNEs in Vietnam suggest that in a number of cases there is virtually no linkage with the apparel sector in the host country. For example, Shinwon Ebenenzer, a Korean apparel MNE, invested in Vietnam to set up its garment factory since 2002 and employs a dozen thousands of workers. The company receives orders from the parent company in Korea to produce for GAP, Old Navy, and TJ Max, and imports materials (almost 100 per cent from China and Korea) and exports all of its production. The contribution to local economy is mostly through employment generation. 
For the apparel sector it is also difficult to connect with mediumsized Korean firms to be part of the global production networks. An example is Vietnam Kumyang, a Korean FDI firm in Vietnam, which invested in Vietnam since 2005. The company has until now created limited connections with the local economy, except for employing workers and mid-level management. The company imports 100 per cent of its materials from China and produces for orders from larger MNEs in which the terms and conditions of processing contracts already specify the source of materials. The strategy of Vietnam Kumyang is to take advantage of cheap labour, like Shinwon, and it has basically no interest in working with local Vietnamese firms, hence little connections with them.

The two cases above illustrate an important point - the investment strategy of MNEs when investing in the host country is critically important. These two companies invest in Vietnam to produce for orders from larger MNEs and take advantage of cheap labour. These companies do not create any connection with local firms, very little spillover effects and in many cases compete with local firms. It is also these types of FDI firms that will compete furt with Vietnamese firms, both large and SMEs, when the forthcoming rrans-Pacific Partnership (TPP) come into force with the customs duties on the textiles and apparel exported by Vietnam and other TPP parties and vice versa will be eliminated either immediately or over longer timeframes. ${ }^{10}$ Contrary to our expectations that such FTAs would be beneficial to SMEs, it has been argued that AEC and TPP would benefit the larger firms and FDI firms rather than general and smaller firms like SMEs. With the ever reduction of tariff toward zero rate, there is a corresponding increasing trend of FDI inflows into Vietnam. Theoretically it would create more opportunities for Vietnam SMEs. However, in reality due to the lack of capacity the larger MNEs from Korea (and Taiwan) would "import" the whole value chains, i.e. from providing inputs, components to processing in Vietnam so that they would be qualified as having Vietnam's origin to benefit from such trade agreements. As a result, smaller SMEs would be driven out of the value chain due to their lower capacity and higher competition with an ever decreasing margin (processing fee would be on the decrease). In addition, thanks to their size and hence economy of scale, it is typically the larger firms which would benefit from the agreements, i.e. meeting the stricter and more stringent requirement of the agreements. Our interviews with these 
Korean FDI firms suggest that there would be more competition for Vietnamese SMEs. For example, Shinwon has just established a Shinwon company in Ho Chi Minh City in order to seek orders from Vietnam, rather than through its parent in Korea. It is also very unlikely that Shinwon would change its production mode in Vietnam, i.e. shifting toward connecting with garment processing SMEs.

\subsection{Participation in Global Production Networks in the Advanced Electronics Sector}

\subsubsection{An update on the sector}

Since 2011, electronics has overtaken textile as the top sector in terms of export value (see Figure 11.3). ${ }^{11}$ The spectacular growth during the last few years that Vietnam's electronics sector has experienced is especially due to the arrival of large electronics MNEs, many of whom are Korean MNEs such as Samsung and LG among many others, which establish their production hubs in Vietnam, partly in response to the rising wages in China and partly due to their China plus one strategy, i.e. large firms are moving to Vietnam in order to reduce their production costs, while at the same time still locate near to their markets and reduce their dependency on specific countries or suppliers. According to the General Statistics Office, from 2007-11, the total number of firms in the sector increased 69 per cent from 305 firms to 516 firms, and the number of jobs created in the sector has soared more than two times, from more than 78,000 to nearly 170,000 . According to Vietnam Electronic and Informatics Association, by 2012, out of the 500 electronics enterprises, one third are foreign firms. The electronics sector now employs about 500,000 employees.

With the increased electronics FDI inflows, it has been highly expected that Vietnam would soon be able to integrate into the electronics global production networks with both the export and import of electronics increasing. At the moment it can be said that the global production networks start to take root in Vietnam with the presence of world leading electronics firms who are operating in all tiers of the electronics supply chain such as Intel which produces semiconductor components, Foxconn and Compal, which function as electronics manufacturing service (EMS) providers and original design manufacturers (ODMs) respectively, and Samsung, LG, Nokia and Canon, which are original equipment manufacturers (OEMs), but also do final 
FIGURE 11.3

Vietnam's Key Exports: Electronics a Rising Sector (USD million)

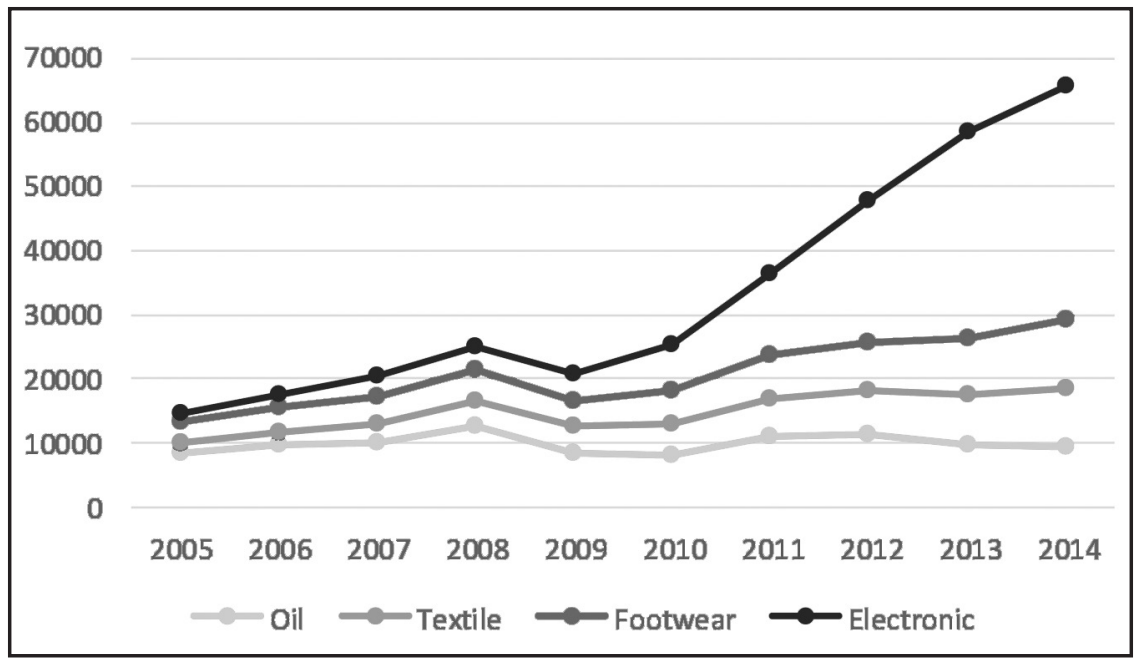

Source: UN Comtrade.

assembly and customization. ${ }^{12}$ The recent arrival of electronics FDI firms in Vietnam can be attributed to the efforts by the government to lure these hi-tech companies to Vietnam with the hope that their arrival would bring about employment, capital, and spillover effects for industrial upgrading by local firms in Vietnam. At this stage, we would like to address the question whether Vietnamese local electronics firms could integrate into the electronics global production networks. Given the current status quo policy regime, local SME firms in general would find it hard to integrate into the value chain and the process is not automatic.

Despite its spectacular growth, the domestic/local value added of these ever increasing exports and imports is very low due to limited participation of local firms in the production value chain and the labour cost accounts for a very small fraction (as low as only 1-2 per cent) of the total value for certain MNEs in Vietnam. ${ }^{13}$ Almost all of the experts we interviewed share the view that such spectacular growth was due to FDI companies like Samsung, Canon, Nokia and LG while Vietnamese local electronics companies make up less than 20 per cent of the domestic market and nearly 5 per cent of the export turnover. 


\subsubsection{Participation in Korean Electronics Production Network}

Integrating in global electronics production networks, including Korean MNE-led networks, has been proven to be difficult for Vietnamese electronics firms. It is rare to find Vietnamese electronics firms which are able to become direct suppliers to electronic giants. In this section, we attempt to answer the question: Can Vietnamese firms, especially SMEs, establish a supplier-client relationship with large MNEs like Samsung? Our interviews with both FDI and domestic electronics firms indicate that there may be isolated cases where direct link is possible, however, this is the exception rather the norm. There are a number of reasons for this.

First, the nature of the electronics sector is characterized by (i) both capital and technologically intensive; (ii) modular production and stringent technical requirements (high quality, large volume, justin-time delivery); and (iii) high competition and low margin. As local Vietnamese firms which are often small and have only limited capacity (both financially and technically), they are unable to adopt modular production to compete on low margin to integrate into global value chains led by large MNEs. At the moment, even if the leading electronic companies investing in Vietnam would like to source inputs from local firms to decrease production cost, the limitation in production capacity of domestic firms mainly prevent this process. Samsung Electronics Vietnam has only seven Vietnamese partners in its 93 suppliers, and these Vietnamese firms only provide packaging and printing services while other suppliers are mainly companies from South Korea or other ASEAN countries, or FDI firms in Vietnam. ${ }^{14}$ It has been reported that under pressure from the government, Samsung Vietnam has been reaching out to Vietnamese SMEs offering training and coaching to assist SMEs to qualify as Samsung suppliers but so far the results have been minimal because like other MNEs, Samsung is operating an open and competitive tendering procedure to select the most competitive and capable suppliers based on price, quality and time delivery. On the part of the local Vietnamese private firms, they would have little incentive to invest in technological capability to meet the standards imposed by these MNEs unless the government has concrete policies and actions. First, working in manufacturing and being suppliers to these MNEs is not easy and due to the potential intensive 
competition, the margin is generally low, discouraging firms away from manufacturing including electronics. Second, working with MNEs, taking on more tasks/jobs and moving up the value chain involved extra-proportional risk which the government should be willing to compensate for.

Secondly, like most modern manufacturing industries, the global electronics sector has a tiered production structure, ${ }^{15}$ under which the brand manufacturer is designated as an OEM. The second tier is the contract manufacturer. These are either ODMs that design the products to meet the OEMs' requirements or EMS providers that manufacture according to the designs provided by the OEM. The third tier is the producer of components that supply inputs to the contract manufacturers. The fourth tier is the producer of the basic materials used to produce the components.

Due to its tiered structure, it would be extremely difficult for Vietnamese SMEs to participate, integrate and move up the value chain and become first-tier suppliers to Korean MNEs. For example, in the case of Samsung which has invested heavily in Vietnam. Despite optimistic speculations that the arrival of the firm in itself presents an important opportunity for local Vietnamese firms to integrate into the global production networks, to move up the value chain and upgrade its industrial capability, out of nearly 100 suppliers for Samsung in Thai Nguyen there are only seven local Vietnamese firms which are suppliers of packaging and logistics (non-core electronic businesses). ${ }^{16}$ The remaining suppliers are Korean and FDI firms. ${ }^{17}$ At the moment Vietnamese-owned firms, most of whom are SMEs, are not "qualified" as they are unable to meet the high technical standards required by Samsung. In response to government initiatives to connect potential Vietnamese suppliers with Samsung, the company provides a list of 170 parts and components it would like to source from Vietnam. Vietnamese firms, however, are unable to produce a single component, even a screwdriver, that meets the technical standard, be delivered on time and at a competitive price. It is therefore most likely that Vietnamese firms would only be able to supply to firsttier and second-tier suppliers of Samsung. What may be needed now are the specific and nuance incentives and policies to induce local Vietnamese firms to upgrade. However, all electronic enterprises, including those firms with 40-50 years of experience, are unable to 
produce the simplest components such as battery charger, USB cable, etc. The managers of Samsung find the target of having half of the 170 providers of Samsung be Vietnamese firms by 2015 difficult to accomplish. ${ }^{18}$

In addition, for global production networks like electronics, both the inbound and outbound supply chains are managed globally. Inputs are also sourced and delivered globally, using the parent company's distribution network and thus subject to the same standards and requirements. The local managers in Vietnam would have little say in sourcing decision from Vietnam. The fact that Vietnamese firms at the moment could not meet these standards could also be an excuse for large MNEs to source from outside of Vietnam or from the traditional suppliers.

Thirdly, the "follow-the-leader effect" would lead to the creation of the whole supply chain in Vietnam by MNEs and their FDI suppliers. Due to the tiered structure when the MNEs (leaders) invest in Vietnam, they attract their followers ("follow-the-leader effect") - their suppliers to build factories in Vietnam, creating a whole value chain for the original MNEs at the exclusion of local SMEs. These suppliers will import parts to be assembled into components that are then delivered to their clients' factories. It is likely that over time they will increase the amount of locally-produced parts they use. Eventually the brand manufacturers may procure components from local producers. This is a positive scenario. But another scenario is also possible - that is the follow-the-leader effect by MNEs' suppliers may pre-empt and crowd out investment by local Vietnamese firms.

Seoul Metal (SM) is a good case to demonstrate the "follow-theleader effect" whereby smaller firms follow the lead MNEs in investing overseas. While the follower firms may help fill in the vacuum of missing supporting industries in the local economy, they limit the potential for the development of local SMEs to integrate into the global production networks. Established in Vietnam in 2008 with an initial capital of US\$9.6 million, SM produces screwdrivers of various types for mobile phones and other electronic products, with production facilities in Korea, China, Philippines, Indonesia and Vietnam. Since Samsung increased its investment in Vietnam, so did SM. Currently, SM employs 100 Vietnamese workers and 34 Korean employees. Its customers include Samsung (60 per cent of total production) and 
others like Brothers, Nissei, and Panasonic (40 per cent). Due to the fact that the parent company SM in Korea is a long-time supplier to Samsung, its original intention to invest in Vietnam is to supply to Samsung, hence "follow-the-leader" effect. The main reason SM invests in Vietnam is to follow Samsung. They could relocate their production factory to other countries with ease. There is no linkage with local Vietnamese firms. SM has only one subcontractor (for coating, painting and galvanizing the screwdrivers) and this subcontractor is also a Korean FDI firm. ${ }^{19}$ The two share the same production premise. Before moving to Vietnam, SM and this subcontractor have already been doing business with each other. When investing in Vietnam, $\mathrm{SM}$ do not need to look for local Vietnamese contractors. According to SM, the reason they do not choose Vietnamese contractors is because they are afraid that local Vietnamese firms are not capable of delivering on a large scale and within stringent timeline. The production would require intensive investment in technology, capital, and machinery, especially specialized equipment. For example, in the case of Samsung, the procurement section will ask for quotations (valid for a limited period of time) from various suppliers for supplies of certain technical specifications, with a given volume and delivery time. In addition to meeting the delivery time and the capacity to supply on a large quantity, suppliers will have to compete by driving down their prices which is only possible if producing on a large scale.

Similar to the apparel sector, there are Korean FDI electronics companies that invest in Vietnam just to take advantage of the country's cheap labour cost and incentives offered by the government, ${ }^{20}$ but develop little connection with the local firms. For example, Crucial Tech is a Korean firm with production facilities in Korea (producing software and chips), China (mobi phone cover and touch pad) and Vietnam (assembly). The factory in Vietnam mainly assembles fingerprint identification touch pad for mobile phones for such customers like RIM, Fujitsu, and Sky. The company exports 100 per cent of its production, 50 per cent back to the parent company and 50 per cent directly to customers. It employs about 100 employees, mostly women, and about ten so-called R\&D staff. The company has little linkage with local firms, it imports virtually 100 per cent of its inputs for production - mainly assembly in Vietnam to take advantage of 
the cheap and skillful workers. It only uses logistics services and some non-electronics materials (e.g. glue) for its production. This case illustrates that though Vietnam can obtain a certain volume of record high-tech exports, the value added to the local economy is very much limited except for a small number of jobs created at the expense of tax incentives.

The only case of the 4P company that has been able to become a supplier to LG is an exception. In the case of the $4 \mathrm{P}$ company, ${ }^{21}$ it was established in 2001 by two entrepreneurs, both of whom previously worked as employees for LG Vietnam. Having worked for LG for many years, they decided to leave and establish $4 \mathrm{P}$ company with the intention of becoming a TV-component supplier of LG, which is now its biggest customer. As early as 2001 when first starting up the business, the $4 \mathrm{P}$ owners invested as much as US $\$ 1.8$ million. After 13 years in operation, $4 \mathrm{P}$ has become the leading Vietnamese electronic manufacturer and has been experiencing technological upgrading thanks in part to the knowledge transfer from LG. ${ }^{22}$ However, the focus is still on assembly manufacturing rather than producing chips and components, which is a very capital and technological intensive business and the company has not yet planned to move into that area. Linkages from $4 \mathrm{P}$ to other companies are quite limited and there is also little spillover from $4 \mathrm{P}$ to the rest of the sector. The company only uses carton boxes from domestic suppliers while main components are imported from China, Korea, Taiwan, Indonesia and Malaysia.

On its own MNEs have little incentive to transfer technology to local suppliers (who might potentially become their competitors), but at the same time, in order for their suppliers to be able to meet their "specific" requirements, some transfer of technology and/or industrial upgrading must happen for $4 \mathrm{P}$ to be able to meet MNEs' requirements. $4 \mathrm{P}$ has been able to upgrade by (i) learning directly from these MNEs on specific requirements - usually training will be provided by MNEs; and (ii) using external consultants and training its own staff for general technological capability $-4 \mathrm{P}$ sends their technical taff to Korea for technology transfer purposes and recruit foreign technicians when the company introduces new machines and technology. The company also has a technical process in place to meet the stringent requirements by MNEs by having an extensive testing system. 


\subsection{Integration by Working with Medium-sized Korean Firms}

The discussion thus far focuses on the two key sectors and the linkages with Korean MNEs. Evidence so far tends to suggest that integrating into global production networks by directly engaging with MNEs would be out of reach for most Vietnamese SMEs. It seems that the way forward for Vietnamese SMEs is to work with small and medium firms which are more tenable for Vietnamese firms' capacity. In this section, we present a case of "successful cooperation" between a Korean FDI firm and a local manufacturing SME, in which we observe a number of types of industrial upgrading: (i) product upgrading, i.e. the $0.5 \mathrm{~mm}$ steel tube that meets the requirements of Samsung was introduced; (ii) process upgrading with new equipment being tested and adapted into a new production process suitable for the company's own production technical requirements; and (iii) functional upgrading within the same value chain with the local company being able to assume more and more tasks from the Korea partner. The case is also selected to highlight a number compatibility issues between the two which simply do not exist in the relationship between Vietnamese SMEs and large MNEs. The Korean FDI firm in our analysis is Ys Tech company (YT) which is a small and medium FDI firm with an investment capital of US\$5 million and the Vietnamese SME firm is Eco Vietnam (EV) which was established in 2010 with a small investment capital of VND 3 billion (equivalent to US\$200,000).

Investing in Vietnam, YT's plan was to become a Samsung supplier. However even for a Korea-origin company, it was not easy to meet Samsung's requirements. The company only secured its first contract with Samsung in 2012, supplying three key components namely tubes, carbon brush, and motor, among which the most technically challenging is the tube. The company faced with a dilemma: importing tubes from China proves unprofitable but producing tubes in Vietnam at a lower cost than China imports was unfeasible due to the lack of competent suppliers. The strategy adopted was to import from China while searching for local partners. On the other hand, EV was making no profits, mainly producing domestic appliances such as clothes hangers, and cupboards. In 2012, EV decided to move into the so-called supporting industry with an aim to linking up with international partners. After four years of looking for the right partners, YT chose EV as a potential partner so that they could collaborate and transfer the necessary vacuum cleaner tube production 
technology. After years of intensive technical collaboration, EV is finally able to meet the technical requirements not only by YT but also by Samsung - that is to produce tubes of $0.5 \mathrm{~mm}$ thickness.

On their part, being a smaller FDI investor in Vietnam, YT always has the incentive to work and interact with local partners in order to find "innovative" ways to do things (i.e. doing whatever it takes). YT has had a hard time finding partners in Vietnam, as Vietnamese firms are not keen to acquire skills and technology as the returns from doing so in manufacturing where the margin is very low may not be enough to compensate for the risks involved. ${ }^{23} \mathrm{YT}$ does not only create jobs for the local labour force like other foreign-invested enterprises but more importantly, it transfers technology to EV, sets up a partnership with EV, and then makes EV a second-tier supplier for Samsung, acting as a bridge between a Vietnamese supplier (EV) and Samsung. This has pushed this Vietnamese firm to actively participate in the global production networks. On their part, EV has a number of "right conditions" to make things happen. First the founder of EV used to be a manager of a Japanese firm in Vietnam which gave him exposure to technology and management skills (Kaisen or 5S) and experience. Secondly, the company made a strategic decision to enter the supporting industry, and hence later, successful built a partnership with YT. The cooperation, the transfer of technology and the functional upgrading are possible because it is beneficial to the two companies: produce products of better quality and cost-saving (reduced damage caused to final products when transporting in intermediate forms).

\section{Conclusion}

This chapter attempts to investigate the significance of regional integration for SMEs of developing countries to integrate into global value chains. As a case study, this chapter looks at Korean MNEs investing in Vietnam, especially in the garment and electronics sectors. The chapter addresses two related questions. Firstly, how MNEs are affected by regional integration in their investment decisions. And secondly, how these Korean MNEs establish linkages with local SMEs.

Recent regional integration does have strong impact on the investment decision of MNEs, although it is not the single important factor and 
certainly not the most important factor. Korean MNEs, especially, choose Vietnam for its cheap labour, political stability, and government incentives. Secondly, integration into global production networks / value chains is not a simple task and should not be taken for granted for SMEs in developing countries. Working in a global production network requires firms involved not only to be highly competitive in terms of price and technical requirements, but also be able to deliver in large volumes on a very stringent time schedule. It is the highly competitive nature of the business and the relatively low margin that makes integration by SMEs difficult.

From the local firms' perspective, doing business within the global production networks is a tough task (competitive, low margin, capital intensive, higher requirements). There should be policies to compensate for those firms willing to take risks in integrating into global production networks. This is important even for firms to upgrade within the value chain. Taking more tasks (upgrading) involves more risk (for example, when garment firms take on the role of procurement, they have to bear credit risk, which is the risk of loss resulting from the customers' failure to accept the final goods and make payment after the garment firms have expended the money to purchase materials, produce and deliver the goods to them). Without government support, it would be difficult for them to take on more tasks, especially for SMEs.

In order to develop the SME sector, additional efforts by policymakers are required to encourage integration into the global production networks. A lesson could be learnt from China's experience in developing its electronics sector (Chen 2014). In China, while the government of Suzhou selectively works with large scale leading MNEs and provides them with priorities and incentives, the government in Shenzhen opts for smaller scale FDI. The end result is that Chinese domestic firms face variable markets whereby those in Suzhou are stuck in the race to the bottom on costs, while their counterparts in Shenzhen develop their capacity and climb up the value chain. As pointed out by Lin Chen (2014), by partnering with large MNEs, the government in Suzhou and MNEs create a "supply gap" between these global MNEs and the domestic firms. This gap encourages MNEs to adopt a "group-offshoring" strategy - bringing the whole value chain within the country. This would further create the power 
disparity between the leading MNEs and local firms - squeezing local firms into the bottom of the value chain. In contrast, by first working with smaller FDI firms, the government in Shenzhen facilitates the upgrading of local firms. Our case studies above also point to a similar story: local firms could supply and move up the value chain by working with smaller FDI firms. Attracting large FDI firms such as Samsung and Nokia would surely be a policy target. However, simply attracting large FDI into Vietnam may not guarantee the technological upgrading of local Vietnamese firms. It would require additional policy design and efforts to make sure that upgrading happens.

\section{NOTES}

1. Acknowledgement: This chapter is prepared within the framework of the project: SME Participation in ASEAN and East Asian Regional Economic Integration managed by Economic Research Institute for ASEAN and East Asia (ERIA). The authors would like to thank Cassey Lee, Dionisius A. Narjoko, Sothea Oum and other reviewers for their helpful comments. The authors would also like to thank representatives from companies who agreed to be interviewed by our team. The usual disclaimer applies. The views expressed in this chapter are those of the authors and do not necessarily reflect the views or policies of the institutions that the authors are associated with.

2. The lists of the Free Trade Agreements engaged into by any of the 48 ADB member countries/economies in Asia and the Pacific with another country or an economic bloc within or outside the region can be found at $<$ https: / / aric.adb.org/fta $>$.

3. <https: / / aric.adb.org/fta-trends-by-country>.

4. Developing countries may try to develop particular niche location advantages in order to attract production blocs, rather than attempt the more difficult task of country-wide fundamental improvement of the investment climate. With fragmentation, it would be much easier for less developed countries (LDCs) to start industrializing than in the past by attracting some pieces of production blocks.

5. Vietnam Kumyang in Vinh Phuc (medium) and Shinwon Ebenezer in Bac Ninh (large). Ideally we would like to interview newly established FDI firms in Vietnam. However arranging interviews with these new firms proved difficult. Instead, we rely on interviewing these two firms, and asked for 
their opinions on the impacts of regional integration on other firms and the sector.

6. Viet Nam News, "VN Not Ready to Join Global Value Chains", 11 December 2014, available at <http:/ / vietnamnews.vn/economy/263874/vn-not-readyto-join-global-value-chains.html>.

7. This may be in part attributable to rising labour costs, strengthening environmental regulations in China and appreciating RMB, which all have led to the shifting of orders by the world's leading importers, including the European Union, the United States and Japan from China to other Asian developing countries, such as Bangladesh, Vietnam and Cambodia. Many Chinese and Hong Kong apparel manufacturers also relocated their low value-added activities to these countries while focusing on the more sophisticated and higher value-added activities or urgent orders.

8. Other methods generating higher value added accounted for only the remaining modest share (15 per cent), including Original Equipment Manufacturing/Freight on Board (OEM/FOB), Original Design Manufacturing $(\mathrm{ODM})$ and Original Brand Manufacturing (OBM). Vietnamese companies undertaking OBM usually distribute their products solely in the domestic market.

9. The larger Vietnamese suppliers, such as members of Vinatex group, would be able to engage with MNEs.

10. Currently, according to Vinatex, the average rates of import taxes on the textiles and apparel are 12.4-20.0 per cent in the United States, and 9.29.4 per cent in the European Union, which are the two largest markets worldwide. These agreements, therefore, make the exporters located in Vietnam become more attractive to the importers than those in other countries, including China, Bangladesh, India and Cambodia. To benefit from preferential access, these products are nonetheless required to strictly meet the rules of origin. The heavy reliance on the input materials imported from China might therefore deter many Vietnam's enterprises from utilizing these agreements. The TPP provides a separate chapter (Chapter 4) concerning this industry with flexible articles related to the rules of origin. In particular, the short supply list allows 194 types of fabrics, yarns and fibres to be sourced from non-TPP countries, and used in the apparel production in the TPP region without losing duty preference.

11. There was an earlier period that the sector experienced significant development. It was during the 1990s, when the economic reform led to the arrival and return of foreign investors. Among the first to arrive were Japanese electronics investors and this was followed by Korean investors. This period was characterized by a large number of joint ventures between FDI electronics firms and domestic firms. Electronics products (assembled from imported parts and components mostly by joint ventures) were even 
exported to non-traditional markets outside the former social union countries. In the domestic market, such names as Viettronic Dong Da and Viettronic Tan Binh were popular for consumer electronics products and competed successfully against second-hand imports from Japan. By the end of the 1990s, the electronics industry had over 100 factories assembling consumer electronics products. Despite its success during these earlier years, the sector suffered a number of limitations and weaknesses for a variety of reasons that may hinder the long-term development of Vietnam domestic electronics firms and this only came to the fore when Vietnam joined the World Trade Organization. They include: (i) lack of technological upgrading; (ii) being trapped in the low-productivity labour intensive processing/assembling jobs; (iii) being excluded from global production networks. The local Vietnamese electronics sector has had to pay a dear price for this. Today, most of these joint venture factories are either out of business, diversifying into other sectors, or trying to survive by taking on processing contracts for the workers. Their roles are getting smaller in the electronics sector of Vietnam.

12. Taiwan's Foxconn Group on 28 August 2013 opened two hi-tech factories with a combined investment of US\$80 million in the northern province of Bac Ninh. The two factories, built on 1.1 hectares of land in the Que Vo Industrial Zone, manufacture hi-tech products such as cameras, computers and electronic appliances. Foxconn CEO Try Guo said the two abovementioned projects are just the start of the Group's ambitious Vietnam investment strategy that will eventually mushroom to over US\$5 billion and make Foxconn the largest foreign investor in the second fastest-growing economy in Asia. The other big investors include: Brother Vietnam (Japan), US\$25 million, December 2012; Nidec Seimitsu (Japan), US $\$ 40$ million, July 2012; SOC Vietnam (Japan), US\$62.5 million, November 2012; JBL (USA), US\$100 million, June 2012; Terumo BCT (USA, Japan), US\$94 million, May 2012; Kyocera (Japan), US\$320 million by 2013, October 2012; Hitech BSE (South Korea), US\$30 million, April 2013; Fuji Xerox (Japan), US\$120 million, November 2013; Nokia (Finland), US\$300 million, early 2013; Samsung Electronics (South Korea), US $\$ 2.2$ billion by 2020, November 2012; Samsung Display (South Korea), US\$1 billion by 2020, March 2014; Laird (British), US\$10 million by 2015, January 2014; Nokia, US\$220 million, May 2014 (moving a large number of production lines from factories in China, Hungary and Mexico to Vietnam).

13. Despite the huge export revenue, the local added value is low which is typical in any global production network. For example, the iphone supply chain where value added for China is about US\$8 out of US\$500 price tag. See <http:/ / skhdt.bacninh.gov.vn/Index.aspx?item=19\&item=18\&ba=19\&new= 304\&giai-phap-nang-cao-gia-tri-gia-tang-trong-xuat-khau-hang-hoa-cua-cacdoanh-nghiep-fdi-tren-dia-ban-tinh-bac-ninh.html>. 
14. For example, Intel has only 18 Vietnamese partners among hundreds of companies providing materials and components for its production. See "Thoi co cho công nghiep ho tro", Báo Nguoi Lao Đong Online, 11 September 2014, available at <http://nld.com.vn/ kinh-te/thoi-co-cho-cong-nghiep-ho-tro20140911222258601.htm>; "Electronics Industry in Dead Throes, VN has to Start Again from Scratch", VietNamNet, 8 October 2012, available at $<$ http: / / english.vietnamnet.vn/fms / special-reports / 49741 / electronics-industry-indead-throes--vn-has-to-start-again-from-scratch.html> or "Electronics Sector in Need of Support", Viet Nam News, 3 May 2014, available at <http:// vietnamnews.vn/ economy / 254345 / electronics-sector-in-need-of-support. html>.

15. At the top is the brand manufacturer (producer-led production network like Samsung) or retailer (retailer-led production network like Nike), which distributes the branded products to consumers.

16. VN Express, "Tuyen doanh nghiep làm oc vít, sac pin cho Samsung", 11 September 2014, available at <http:/ / kinhdoanh.vnexpress.net/tin-tuc/ doanh-nghiep/tuyen-doanh-nghiep-lam-oc-vit-sac-pin-cho-samsung-3078103. html>.

17. Samsung attracts a lot of media attention and the arrival of the conglomerate has sparked a lot of hot debates concerning the failure of the supporting industry and the strategy for Vietnamese firms to become suppliers to Samsung as the company keeps investing in large projects in Vietnam with total investment reaching US\$11.2 billion. Samsung built its first electronics factory in Bac Ninh in 2008 and started its operation in 2009. In 2013, Samsung Electronics opened another plant in Thai Nguyen with an investment capital of around US\$2 billion. Two more plants are expected to be operating in 2015. An investment project to set up Samsung Display in Bac Ninh was approved in 2014 and Samsung CE Complex in Hi-tech Park Ho Chi Minh City was licensed on 1 October 2014. According to Mr Shim Won Hwan, President of Samsung Vietnam Group, Vietnam is becoming the largest Samsung production hub. "Samsung tro thành nhà đau tu nuoc ngoài lon nhat tai Viet Nam", Vietq.vn, 12 November 2014, available at <http:/ / vietq.vn/nha-dau-tu-nuoc-ngoai-lon-nhat-viet-nam-lasamsung-d45610.html>.

18. See <http: / / www.thanhniennews.com/ business/vietnam-to-lose-fdi-due-toailing-support-industries-24245.html>. For Intel, product samples from domestic firms are very good but when they come to actual business and have to produce a mass quantity, their qualities and deliveries are not consistent.

19. Like Crucial Tech, this company, indeed, purchases some materials from local firms such as protective gears, clothing and some chemicals. However, for its main production and components like steel, cooper, and others, it either imports or purchases from other Korean firms. 
20. The company was awarded the High-Tech certificate by the Ministry of Science and Technology and is eligible for an extended tax exemption at zero per cent.

21. The company has been able to supply to other MNEs, not just to the one that they once worked for and gradually integrate into the global production networks. A very interesting development is that when we visited the company in 2015 , there were signs that $4 \mathrm{P}$ may also become a supplier to Canon and second-tier supplier to Samsung. However, under pressure by LG, the company has focused its production for LG only. Interestingly, when LG invested US\$600 million in Hai Phong industrial park, the 4P company also invested US\$80 million in the same location to improve its production capacity and maintain close proximity to LG.

22. The company is now investing in a US $\$ 80$ million factory in Haiphong to supply for LG. In their agreement with LG, 4P will invest in machinery and equipment, while LG will provide the land rent-free, which will later be a factor in the price of products supplied to LG. The company is investing in Haiphong to produce car electronics for LG.

23. The key reason for $\mathrm{YT}$ to choose $\mathrm{EV}$ is the risk-taking entrepreneurship of the Vietnamese partner. YT has provided technical support to EV for a year so the two firms could produce products that can meet the technical requirements and at a competitive cost/price.

\section{REFERENCES}

Anwar, Sajid and Lan Phi Nguyen. "Foreign Direct Investment and Trade: The Case of Vietnam". Research in International Business and Finance 25, no. 1 (2011): 39-52.

Arnold, Jens M. and Beata S. Javorcik. "Gifted Kids or Pushy Parents? Foreign Direct Investment and Plant Productivity in Indonesia". Journal of International Economics 79, no. 1 (2009): 42-53.

Athukorala, Prema-chandra and Tran Quang Tien. "Foreign Direct Investment in Industrial Transition: The Experience of Vietnam". Journal of the Asia Pacific Economy 17, no. 3 (2012): 446-63.

Chen, Lin. "Varieties of Global Capital and the Paradox of local Upgrading in China". Politics and Society (2014): 1-30.

Chen, Zhihong, Ying Ge, and Huiwen Lai. "Foreign Direct Investment and Wage Inequality: Evidence from China". World Development 39 (2011): 1322-32.

Clark, Don P., Jannett Highfill, Jonas de Oliveira Campino, and Scheherazade Rehman. "FDI, Technology Spillovers, Growth, and Income Inequality: A Selective Survey". Global Economy Journal 11, no. 2 (2011). 
Damijan, Joze P., Matija Rojec, Boris Majcen, and Mark Knell. "Impact of Firm Heterogeneity on Direct and Spillover Effects of FDI: Micro-Evidence from Ten Transition Countries". Journal of Comparative Economics 41, no. 3 (2013): 895-922.

Driffeld, Nigel and Sourafel Girma. "Regional Foreign Direct Investment and Wage Spillovers: Plant Level Evidence from the UK Electronics Industry". Oxford Bulletin of Economics and Statistics 65 (2003): 453-74.

Feliciano, Z. and R. Lipsey. "Foreign Ownership, Wages, and Wage Changes in U.S. Industries, 1987-92". Contemporary Economic Policy 24 (2006): 74-91.

Fukase, Emiko. "Foreign Wage Premium, Gender and Education: Insights from Vietnam Household Surveys". The World Economy 37, no. 6 (2014): 834-55.

Hanson, Gordon H. "Should Countries Promote Foreign Direct Investment?" UNCTAD G-24 Discussion Paper Series No. 9 (2001).

Harrison, Ann E., Inessa Love, and Margaret S. McMillan. "Global Capital Flows and Financing Constraints". Journal of Development Economics 75, no. 1 (2004): 269-301.

Hoang, Pham Thien. "Assessment of FDI Spillover Effects for the Case of Vietnam: A Survey of Micro-data Analyses". In Deepening East Asian Economic Integration, edited by Jenny Corbett and So Umezaki. ERIA Research Project Report 2008-1. Jakarta: Economic Research Institute for ASEAN and East Asia (ERIA), 2009, pp. 473-95.

Hoi, Le Quoc and Richard Pomfret. "Foreign Direct Investment and Wage Spillovers in Vietnam Evidence from Firm Level Data". ASEAN Economic Bulletin 27, no. 2 (2010): 159-72.

Jaumotte, Florence, Subir Lall, and Chris Papageorgiou. "Rising Income Inequality: Technology, or Trade and Financial Globalization". IMF Economic Review 61, no. 2 (2013): 271-309.

Jude, Cristina and Gregory Levieuge. "Growth Effect of FDI in Developing Economies: The Role of Institutional Quality". MPRA Paper No. 49321 (2013).

Khan, Mushtaq H. “Learning, Technology Acquisition and Governance Challenges in Developing Countries". Research Paper Series on Governance for Growth. London: School of Oriental and African Studies, University of London, 2010.

Kimura, Fukunari and Ayako Obashi. "Production Networks in East Asia: What We Know So Far". ADBI Working Paper 320. Tokyo: Asian Development Bank Institute, 2011. Available at <https: / / www.adb.org/sites/default/ files / publication/156175/adbi-wp320.pdf>.

La Porta, Rafael and Andrei Shleifer. "Informality and Development". Mimeo, Harvard University, 2013. Available at <http://scholar.harvard.edu/files/ shleifer/files/informality_may27_abstract.pdf $>$. 
Lipsey, Robert E. and Fredrik Sjöholm. "FDI and Growth in East Asia: Lessons for Indonesia". IFN Working Paper No. 852 (2010).

Machikita, Tomohiro and Yasushi Ueki. "Impact of Production Linkages on Industrial Upgrading in ASEAN, the People's Republic of China, and India: Organizational Evidence of a Global Supply Chain". ADBI Working Paper 399. Tokyo: Asian Development Bank Institute, 2012. Available at <https: / / www.adb.org/sites/default/files / publication/156254 / adbi-wp399.pdf $>$.

Meyer, Klaus E. and Nguyen Hung Vo. "Foreign Investment Strategies and Sub-national Institutions in Emerging Markets: Evidence from Vietnam". Journal of Management Studies 42, no. 1 (January 2005).

Mirza, Hafiz and Axele Giroud. "Regionalization, Foreign Direct Investment and Poverty Reduction: Lessons from Vietnam in ASEAN". Journal of the Asia Pacific Economy 9, no. 2 (2004): 223-48.

Morrissey, Oliver and Manop Udomkerdmongkol. "Governance, Private Investment and Foreign Direct Investment in Developing Countries". World Development 40, no. 3 (2012): 437-45.

Nguyen, Anh Ngoc, Nguyen Thang, Le Dang Trung, Ngoc Quang Pham, Chuc Dinh Nguyen, and Nhat Duc Nguyen. "Foreign Direct Investment in Viet Nam: Is There Any Evidence of Technological Spillover Effect". Development and Policies Research Center (DEPOCEN) Working Papers No. 18 (2008).

Nguyen, Trung Kien. "Wage Differentials between Foreign Invested and Domestic Enterprises in the Manufacturing: Evidence from Vietnam". Asia-Pacific Economic Association's Conference 2014, Bangkok, Thailand, 2014.

Phan, Thanh and Ji Young Jeong. "Potential Economic Impacts of the VietnamKorea Free Trade Agreement on Vietnam". East Asian Economic Review 20, no. 1 (2016): 67-90.

Ramondo, Natalia. "Foreign Plants and Industry Productivity: Evidence from Chile". The Scandinavian Journal of Economics 111, no. 4 (2009): 789-809.

Ronald, MacDonald and Muhammad Tariq Majeed. "Distributional and Poverty Consequences of Globalization: A Dynamic Comparative Analysis for Developing Countries". UK: Business School - Economics, University of Glasgow, 2010.

Salonen, Heini. "Registered FDI from South Korea to Vietnam 2001-2013". Third Meeting of the Asia-Pacific Foreign Direct Investment (FDI) Network for Least Developed and Landlocked Developing Countries UNCC, Bangkok, Thailand, 2013.

Schaumburg-Müller, Henrik. "Rise and Fall of Foreign Direct Investment in Vietnam and its Impact on Local Manufacturing Upgrading". The European Journal of Development Research 15, no. 2 (2003): 44-66. 
Seguino, Stephanie. "Is More Mobility Good? Firm Mobility and the Low Wage-Low Productivity Trap". Working Paper No. 423, The Levy Economics Institute, 2005. Available at <http://www.levyinstitute.org/pubs/wp_423. pdf $>$.

Thanh, Vo Tri and Nguyen Anh Duong. "Revisiting Exports and Foreign Direct Investment in Vietnam". Asian Economic Policy Review 6, no. 1 (2011): 112-31.

Thorbecke, Willem and Nimesh Salike. "Foreign Direct Investment in East Asia". Policy Discussion Papers 13-P-003, Research Institute of Economy, Trade and Industry (RIETI), 2013.

Tran, Thi Anh Dao and Dinh Thi Thanh Binh. "FDI and Growth in Vietnam: A Critical Survey". Journal of Economics and Development 15, no. 3 (December 2013): 91-116.

Tran, Van Tho. "FDI and Economic Development: The Case of Vietnam". In Multinationals and Economic Growth in East Asia, edited by Shujiro Urata, Chia Siow Yue and Fukunari Kimura. London: Routledge, 2006, pp. 393 422.

UNIDO and MPI. Viet Nam Industrial Investment Report 2011: Understanding the Impact of Foreign Direct Investment on Industrial Development. United Nation Industrial Development Organisation (UNIDO) and Ministry of Planning and Investment (MPI) Vietnam, 2012.

Van Reenen, John and Linda Yueh. "Why Has China Grown So Fast? The Role of International Technology Transfer". University of Oxford Department of Economics Working Paper 592 (2012): 1-24.

Vo, Thanh Tri and Anh Duong Nguyen. "Experiences of Vietnam in FDI Promotion: Some Lessons for Myanmar". In Economic Reforms in Myanmar: Pathways and Prospects, edited by Hank Lim and Yasuhiro Yamada. BRC Research Report No. 10, Bangkok Research Center, IDE-JETRO, Bangkok, Thailand, 2012.

Von Luebke, Christian. "The Political Economy of Local Governance: Findings from an Indonesian Field Study". Bulletin of Indonesian Economic Studies 45, no. 2 (2009): 201-30.

Wignaraja, Ganeshan. “Engaging Small and Medium Enterprises in Production Networks: Firm-level Analysis of Five ASEAN Economies". ADBI Working Paper Series No. 361. Tokyo: Asian Development Bank Institute, 2012.

Wignaraja, Ganeshan, Jens Krüger, and Anna Mae Tuazon. "Production Networks, Profits, and Innovative Activity: Evidence from Malaysia and Thailand". ADBI Working Paper 406. Tokyo: Asian Development Bank Institute, 2013. 